\title{
College Students' Attitudes Towards Remote Instruction During the Coronavirus Pandemic: Future Directions
}

Excelsior: Leadership in

Teaching and Learning 2021, Vol. 13(2), 96-112

(C) The Author 2021

CC-BY 4.0 International Reprints and permissions: surface.syr.edu/excelsior https://doi.org/10.14305/in .19440413 .2021 .13 .2 .02

\section{(i) Selenid M. Gonzalez-Frey ${ }^{1}$, Keli Garas-York ${ }^{2}$, Corinne M. Kindzierski ${ }^{3}$, and Julie J. Henry ${ }^{4}$}

\begin{abstract}
Undergraduate and graduate education students completed a survey to examine their attitudes toward remote instruction during the coronavirus pandemic. At the conclusion of the Spring 2020 semester in which all courses transitioned from a face-to-face to an online format, students $(N=93)$ were asked to describe what worked well in their courses in regard to their remote instruction experience and, when things did not go so well, what would have helped to make their experience better. The qualitative data were coded, and inductive analysis was used to generate categories (Johnson, 2012; Strauss \& Corbin, 1998). Responses were grouped into labeled categories, and illustrative quotes were chosen to represent categories. Results revealed that remote instruction was somewhat worse than regular instruction. Across all respondents, analysis of responses to the open-ended questions revealed four themes that students believed were integral to remote instruction: (a) communication between students and faculty, (b) flexibility with assignments, (c) increased virtual interaction, and (d) support. Findings suggest how faculty can facilitate and ameliorate remote and hybrid instruction for their students.
\end{abstract}

\section{Keywords}

remote instruction, coronavirus, communication, student-faculty interactions, professional development

\footnotetext{
${ }^{1}$ SUNY Buffalo State

${ }^{2}$ SUNY Buffalo State

${ }^{3}$ SUNY Buffalo State

${ }^{4}$ SUNY Buffalo State

Corresponding Author:
}

Selenid M. Gonzalez-Frey, School of Education, Buffalo State College, 1300 Elmwood Avenue Buffalo, NY 14222

Email: freysm@buffalostate.edu 
The coronavirus (COVID-19) has changed the world with the ripple effects of the pandemic to be felt for years to come (Allen et al., 2020; Politico, 2020). This has impacted every aspect of society including the nature of teaching in higher education settings. Faculty at universities and colleges had to learn how to adapt to remote instruction, while also considering the diverse academic and social emotional needs of students in remote locations. This balance was further challenged by the mandate of social distancing and unequal access to technology. Knowing the importance of sustained communication between faculty and students, professors were stretched in ways unimaginable a year ago. In home offices across the globe, faculty were struggling to foster meaningful, rigorous learning delivered in a novel way using remote instruction.

As faculty and educators that constantly evaluate and reflect on instruction, student feedback is highly valuable to understand where to go next. The centrality of remote instruction that is technologically driven is clear. As such, it is essential to understand students' perspectives and to aptly respond to this feedback. The current study was designed to improve upon remote and hybrid instruction by asking students for their perspectives.

In order to determine how the consequences of the COVID-19 pandemic affected students, undergraduate and graduate students in one teacher education department were given a survey to evaluate their experience switching from regular, classroom instruction to remote instruction. They were asked to assess what worked well in their courses and what would have helped to make their experience a better one. The following research questions were addressed:

1. What were students' attitudes towards remote instruction compared to regular instruction?

2. What specific factors did students identify as helpful to their success during remote instruction?

3. What specific features did students identify as areas for improvement during remote instruction?

\section{Review of the Literature}

\section{Theoretical Perspectives}

This study was grounded in Lave's Situated Learning Theory (Amendum \& Liebfreund, 2019; Lave \& Wenger, 1991; Lave, 1988), and undergirded by Vygotsky's Sociocultural Theory of Cognitive Development (1978) which posit that learning and higher-ordered thinking is supported by a person's social environment and interaction. Specifically, Vygotsky was convinced that learning occurred through interactions with others in our communities including peers, teachers, and other mentors. He recognized that social settings and learning were closely entwined (Kurt, 2020). Therefore, for students to maximize learning, one should implement strategies that are effective in a social context. With this in mind, teachers have the unique ability to control many factors in an educational setting such as tasks, behaviors, and responses. As a result, the more interactive the activities, the more teachers can promote cognitive growth. Common interactive activities used in higher education may include productive discussions, constructive feedback, and collaboration with others.

Lave argues that learning, as it normally occurs, is a function of the activity, context and culture in which it occurs. Social interaction is a critical component of situated learning-learners become involved in a "community of practice" which embodies certain beliefs and behaviors to be acquired. When 
teacher candidates are allowed to engage with peers, faculty and school partners as part of their college experience, they are more likely to report feeling connected within the larger community (Lave, 1988).

\section{Role of the Professional Development Schools Consortium in Facilitating Student Learning}

One way the college in the current study promotes community connections is through our development and maintenance of a Professional Development School consortium. Typically (not during a pandemic), teacher candidates are afforded many learning experiences in P-12 schools as part of the Professional Development Schools (PDS) consortium at our college. Teacher candidates learn about teaching while working side-by-side with in-service teachers in schools. The PDS consortium was established to promote and facilitate dynamic relationships between the college and partner schools, with the guiding principle and conceptualization that teacher candidates benefit from "real world" experiences, maximize growth in college/P-12 partnered professional development, and provide value added dimensions to partner site classrooms. Teacher candidates move through their preparation programs with cohorts completing field placements at partner schools. Teacher education faculty serve as liaisons between school and university, and feedback from school and community stakeholders is sought on a regular basis. The consortium serves as a clearing house for these partnerships and provides professional development while supporting action research conducted collaboratively across stakeholder groups.

Within this role, the PDS consortium provided professional development presentations, workshops, and resources as different needs presented themselves for students and faculty alike. In the current COVID-19 crisis, as P-12 schools and universities have been forced to shift to remote learning, the nature of these "relationships" have changed, while the need for collaboration and partnership is arguably more important than ever. During remote instruction, teacher educators were tasked with creating authentic settings to foster learning in an online environment to grow a community of teachers. In this "new normal," faculty had to find ways to help teacher candidates gain this knowledge as part of a process in an online learning environment mediated by cultural tools and enhanced by remote versions of social interaction.

\section{Student-Faculty Relationships}

Even with the shift to remote instruction, student-to-faculty interaction continues to be important, if not critical. Interacting with faculty in the classroom, during office hours, or in a supportive role is one of the key college experiences associated with student satisfaction. Positive and multiple interactions between students and their professors has been shown to contribute to students' favorable educational experiences as well as their greater academic and personal development (Kim \& Sax, 2009; Lau, 2003; Pascarella, 2006). The literature continually demonstrates a favorable relationship between studentfaculty interaction and a broad range of student educational outcomes (Strauss \& Terenzini, 2007; Thompson, 2001). In general, the research reveals that more contact between faculty and students, both inside and outside the classroom, enhances college students' development and learning outcomes. Those who study communication write about the differences between cultures that engage in highcontext communication which is face-to-face (or perhaps simulated face-to-face over Zoom, FaceTime or a tool such as Blackboard Collaborate) and cultures that emphasize low-context communication such 
as email. High-context communication includes "facial gestures, body language, silence time, eye contact, and proximity" in addition to the words that are exchanged (Würtz, 2006, p.12).

During the pandemic, many students and faculty members who were accustomed to high-context communication during and after class and during office hours were plunged into a world of separation and silence. In times when faculty needed to rely on distance learning and remote interaction, they were challenged to continually seek and refine how best to use technology to communicate.

\section{Use of Technology to Maintain Communication and Relationships}

Even before the pandemic, the past 20 years have been a period of rapid change and adoption of technology within higher education (Levy, 2016; Pence, 2007). The communication tools that faculty can now use (e.g., email, messaging tools) have created opportunities and challenges for higher education as faculty and students communicate more online (Pence, 2007). Email communication plays an integral role in the academic setting in the United States, serving as the primary means of out-ofclass communication (Brooks \& Young, 2016; Levy, 2016). Professors have reported using email for purposes such as making announcements, soliciting questions, and for making appointments with individual students. When students were asked about purposes for emailing professors, they referred to clarification reasons (seeking information about tasks, seeking feedback on assignments or seeking information about course policies) or personal reasons such as trying to get to know the professor better (Ledbetter \& Finn, 2018). Frequent out-of-class communication via email has been shown to be positively associated with student learning and perceptions of instructor rapport (Sidelinger et al., 1015). During the transition from in-person to remote learning during the pandemic, educators were reminded of the importance of maintaining relationships with teacher candidates, as well as the critical importance of providing clarification through email.

\section{Remote Learning}

The COVID-19 pandemic has highlighted significant disparities in education such as unequal access to technology, quality instruction, and resources for students. In addition, many students have experienced learning loss as schools and institutions have shifted to remote instruction. Further, the professional development needs of instructors have become evident (e.g., Goldstein et al., 2020). Particularly challenging for university educators has been the rapid and unplanned shift to remote instruction. For the purposes of this investigation, remote learning is defined as learning that does not take place in a face-to-face (in person) manner. Remote learning or online learning is also referred to as e-learning (Mena, 2007) or distance learning (Anderson \& Dron, 2011).

Remote learning allows students who are not able to attend school to access educational content. It can be used for general school curriculum and special programming (Burdina et al., 2019. However, for remote learning to be effective and purposeful a number of instructional decisions are required. First, students and teachers need to have "a sufficient level of computer proficiency" (Burdina et al., 2019, p. 3). Next, the educator must determine if the learning will take place synchronously (real-time interactions between the teacher and students) or asynchronously (delayed interactions) (Burdina et al., 2019). Typically, course instructors engage in professional development related to technical and instructional design first or while building remote courses across a semester or between semesters prior to teaching the course. Quality remote learning does not consist of simply moving a face-to-face course 
online, which is what took place in the spring of 2020. Fish and Wickersham (2009) stated, "Teaching online requires a faculty member to think differently about teaching and learning, learn a host of new technological skills, and engage in ongoing faculty development for design and development of quality online instruction" (p. 1). The shift to remote learning at the onset of the pandemic did not afford educators this time and extended training to satisfy the qualities of the effective remote instruction.

Another consideration for quality remote instruction includes class interactions between the course instructor and the students as well as among the students. Frequent communication and prompt feedback are hallmarks of higher student satisfaction with an online course (Fish \& Wickersham, 2009). Providing meaningful opportunities for learning and social interactions in an online course can be challenging. Everett (2015) noted that "in order to create a strong sense of community and to help students engage with learning in online courses, instructors need to find ways to help students feel more strongly connected with each other." (p. 72). Dixson (2010) sought to determine what types of online activities were more engaging for students. She found it was beneficial for course instructors to seek out assignments that allow the students to engage in the course content with classmates. Her results showed "Across many types of courses, when students readily identified multiple ways of interacting with other students as well as of communicating with instructors, they reported higher engagement in the course" (p. 8).

Thus, online course instruction takes considerable planning. It is determining how to rework a course for a remote format so that the content is engaging and fosters interaction. It involves training for the course instructor and preparing remote students for the use of technology (Fish \& Wickersham, 2009), Educators who were tasked with switching over to remote instruction during the COVID-19 crisis were not afforded this time or training to ensure delivery of quality online instruction. Accordingly, the task of eliciting feedback from students and reflecting on what was effective is more important than ever as educators are learning, planning, and doing all at once.

\section{Methods}

\section{Participants and Context}

This study took place in a teacher education department at a large comprehensive college, an urban campus of a state university system. Demographic information about the participants is in Table 1 . Participants consisted of undergraduate and graduate students. All graduate students were commuters, with $20 \%$ of the undergraduate students living on campus, and the other $80 \%$ commuters. There were 93 participants who responded to the survey, which was a $13 \%$ response rate. The 26 graduate students represented about $12 \%$ of the graduate students in the department. The 67 undergraduate students who responded represented about $13 \%$ of the undergraduate students in the department.

\section{Survey}

At the end of the Spring 2020 academic semester, all students were sent the survey via email. The surveys were distributed before grades were finalized. The email was sent out by the department secretary and carried the signature of the department chair. The IRB approved protocol indicated that completion of the survey implied consent to use the responses for research purposes. The survey was electronic, and students were informed that responses were anonymous. The survey contained six 
questions. The first two questions asked students, "What is your major" and "What is your year?" Question three asked students, "How was remote instruction compared to regular instruction?" using a Likert scale with five categories. The five categories were "much worse than regular instruction," "somewhat worse than regular instruction," "about the same as regular instruction," "a little bit better than regular instruction," and "much better than regular instruction."

\section{Table 1}

\begin{tabular}{|c|c|}
\hline Total Enrolled in Education Department & 737 \\
\hline Undergraduate & 515 \\
\hline Graduate & 222 \\
\hline \multicolumn{2}{|l|}{ Participants } \\
\hline $\mathrm{N}$ & 93 \\
\hline \multicolumn{2}{|l|}{ Gender } \\
\hline$\%$ Male & $7 \%$ \\
\hline$\%$ Female & $93 \%$ \\
\hline \multicolumn{2}{|l|}{ Racial Identity } \\
\hline$\%$ White & $68 \%$ \\
\hline$\%$ Black or African American & $19 \%$ \\
\hline \% Hispanic & $12 \%$ \\
\hline$\%$ Multiracial or Other Race & $10 \%$ \\
\hline \multicolumn{2}{|l|}{ Academic Year } \\
\hline \multicolumn{2}{|l|}{ Undergraduate } \\
\hline Freshman & 10 \\
\hline Sophomore & 14 \\
\hline Junior & 14 \\
\hline Senior & 29 \\
\hline \multicolumn{2}{|l|}{ Graduate } \\
\hline First year & 18 \\
\hline Second year & 8 \\
\hline
\end{tabular}

Next, students responded to three open-ended questions. Question four asked, "What are some specific things your education professors did that helped you during remote instruction?" Question five asked, "What are some specific things that your education professors could have done better to help you during your remote instruction?" Lastly, students were given the opportunity to write additional comments. Students were given unlimited space to write their responses.

\section{Data Analysis}

Quantitative data were tabulated using Excel. The qualitative data were coded, and inductive analysis was used to generate categories (Johnson, 2012). Responses were grouped into labeled categories, and illustrative quotes were chosen to represent categories. Percentages were used to report the findings. Four codes emerged from the data. The four codes were "communication," "flexibility," "virtual interaction," and "empathy." These codes emerged as the four major themes (Strauss \& Corbin, 1998). 


\section{Table 2}

Coding Scheme for the First Open-ended Survey Questions Assessing What Instructors Did Well to Help Students with Remote Instruction

\begin{tabular}{|c|c|c|}
\hline Category & Definition & Examples \\
\hline Communication & $\begin{array}{l}\text { Instructors provided timely, clear } \\
\text { (specific details), and consistent } \\
\text { information to students either } \\
\text { through email or virtually via video } \\
\text { platforms }\end{array}$ & $\begin{array}{l}\text { kept in contact"; “consistent } \\
\text { emails"; "quick feedback"; } \\
\text { "detailed instructions" }\end{array}$ \\
\hline Flexibility & $\begin{array}{l}\text { Instructors amended assignment to fit } \\
\text { Online and remote mode of instruction } \\
\text { and extended due dates }\end{array}$ & $\begin{array}{l}\text { "adjust assignment to new } \\
\text { mode"; "flexibility with } \\
\text { due dates" }\end{array}$ \\
\hline Virtual Interaction & $\begin{array}{l}\text { Instructors met with students in real time } \\
\text { either one-on-one or as a class to foster } \\
\text { discussion, review assignments, and teach } \\
\text { new course content }\end{array}$ & $\begin{array}{l}\text { "met to bounce ideas off } \\
\text { others and get direction"; } \\
\text { "zoom class session"; } \\
\text { "Blackboard Collaborate } \\
\text { meetings" }\end{array}$ \\
\hline Empathy & $\begin{array}{l}\text { Instructor checked-in with students to offer } \\
\text { empathy, reassurance, understanding, } \\
\text { and/or socio-emotional support }\end{array}$ & $\begin{array}{l}\text { "encouragement and } \\
\text { reassurance"; "understanding } \\
\text { when approached with } \\
\text { concerns" }\end{array}$ \\
\hline
\end{tabular}

\section{Results}

\section{Attitudes Towards Remote Instruction}

The first research question assessed students' attitudes towards remote instruction. The results revealed 12 students (13\%) felt their experience with remote instruction was much worse than regular instruction. Forty-six students (49\%) felt their experience was somewhat worse than regular instruction. Twenty-two students $(24 \%)$ stated their experience with remote instruction was about the same as regular instruction. Six students $(6 \%)$ felt their experience was a little better compared to regular instruction. Finally, seven students ( $8 \%)$ felt their experience was much better than regular instruction.

Figure 1 shows the distribution of students' attitude based on academic year. The figure demonstrates that across academic years, students mostly reported that remote instruction was somewhat worse than regular instruction. Notably, more seniors believed remote instruction was somewhat worse compared to any other academic year.

The second question explored the elements of remote instruction that students found helpful during their experience switching from traditional instruction to remote instruction (see Table 2). Of the 93 participants, 75 answered the question "What are some specific things your education professors did that helped you during remote instruction?" The results showed that $45 \%$ of students who responded to this question stated communication between instructors and students helped them during remote 
instruction. Specifically, 33\% of students noted that communication needed to be timely (i.e., quick), consistent, and clear (i.e., providing specific and detailed information). In addition, of the students that identified communication as important, $45 \%$ stated that proactive and consistent emails from instructors was helpful and $25 \%$ indicated that video conferencing made communication clearer. Furthermore, $19 \%$ of students indicated that it was helpful when instructors used virtual platforms to encourage interaction.

\section{Table 3}

Coding Scheme for the Second Open-ended Survey Question Assessing What Instructors Could Have Done Differently to Help Students During Remote Instruction

\begin{tabular}{lll}
\hline Category & Definition & Examples \\
\hline Communication & $\begin{array}{l}\text { Instructors could have provided more } \\
\text { timely, clear (specific details), and } \\
\text { consistent information to students } \\
\text { either through email or virtually via } \\
\text { video platforms }\end{array}$ & $\begin{array}{l}\text { "answering emails more"; } \\
\text { "been more specific about } \\
\text { directions" }\end{array}$ \\
Flexibility & $\begin{array}{l}\text { Instructors could have amended } \\
\text { assignments to fit online and remote } \\
\text { mode of instruction }\end{array}$ & $\begin{array}{l}\text { "adjust assignment to make } \\
\text { online friendly"; "flexibility } \\
\text { with assignments" }\end{array}$ \\
& $\begin{array}{l}\text { Instructors could have met with students } \\
\text { in real time, either one-on-one or as a class } \\
\text { to foster discussion, review assignments, } \\
\text { and teach new course content }\end{array}$ & $\begin{array}{l}\text { "more online meetings } \\
\text { where we all were in } \\
\text { attendance"; "zoom for a } \\
\text { classroom feel"; "more } \\
\text { interaction }\end{array}$ \\
\hline
\end{tabular}

\section{Figure 1}

Students'Attitude Toward Remote Instruction Based on Their Academic Year

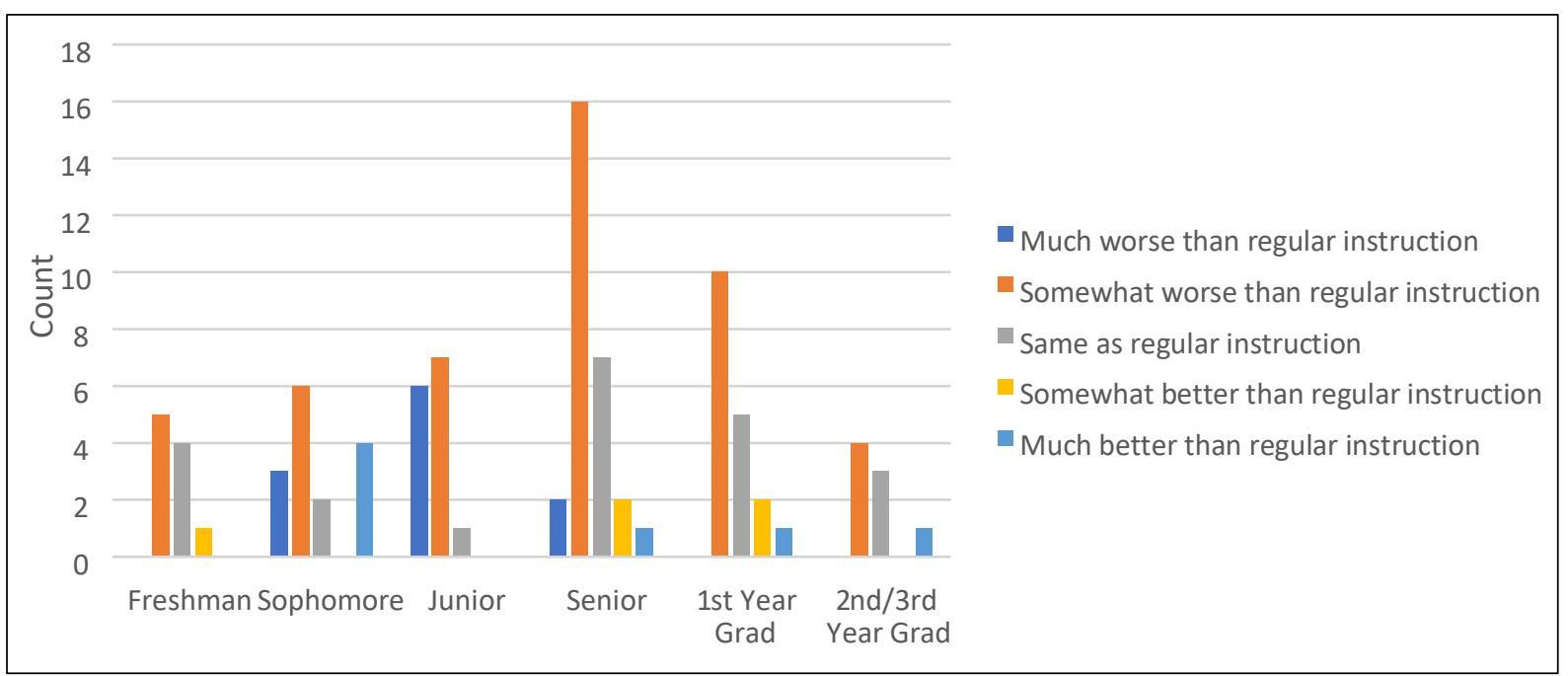


Next, $29 \%$ of students stated that flexibility by the instructor on due date and types of assignment was helpful. Of these students, $45 \%$ specified that extending deadlines during remote instruction helped them to be successful. Finally, results showed the $13 \%$ of students indicated that empathy from instructors was helpful. It made them feel understood and emotionally supported.

The third research question explored the areas of remote instruction that needed improvement. Of the 93 participants, 72 answered the question "What are some specific things that your education professors could have done better to help you during remote instruction?" Survey data were coded and grouped into labeled categories. Three themes emerged from this data (Strauss \& Corbin, 1998): "communication, "virtual interaction," and "flexibility" (see Table 3), mirroring three of the codes from the previous question. The results revealed that $25 \%$ of students who responded to this question stated that communication between instructors and students could have been better. Next, $11 \%$ of students indicated that instructors could have done a better job of using virtual platforms to foster interaction between instructors and students as well as among students. Additionally, $8 \%$ of students stated that it would have been helpful if instructors were more flexible in terms of adjusting assignments. Interestingly, the results revealed that $24 \%$ students stated that nothing needed to be improved, given the circumstances of abruptly switching modes of instruction.

\section{Discussion}

The beginning of the year 2020 brought about challenges for our society, affecting all facets of life. With the quick spread of Covid-19, schools, including institutions of higher education, had to swiftly and abruptly change their mode of instruction to keep students, faculty, and staff safe and to continue providing quality instruction for students. Remote instruction became the mode of instruction. This was the case for the undergraduate and graduate students in the current study. Suddenly, students faced the challenge of having to learn new material while simultaneously adjusting to a new way of learning. This study presents the results from a survey given to undergraduate and graduate students in a teacher education department. Students were asked to describe what worked well in their courses in regard to their remote instruction experience and, when things did not go so well, what would have helped to make their experience a positive one.

Analysis of the data revealed that across academic years, students reported that remote instruction was somewhat worse than regular instruction. The academic semester was upended in an unprecedent fashion requiring educators and students to swiftly develop new ways of communicating, teaching, and interacting. What used to work in a traditional classroom environment was not necessarily effective during remote instruction. Students were affected by these changing times and needed a voice in responding to the situation. Surveying students gives practitioners an opportunity to improve their practices for remote learning, for hybrid instruction, and even for in classroom learning. Students' responses to the survey showed that seniors (more than any other group) were most likely to describe remote instruction as somewhat worse compared to regular instruction. This is not surprising as they did not get the typical closure of their academic careers, especially with the cancellation or postponement of graduations. This may have additionally affected their attitudes towards remote instruction. Across all respondents, analysis of responses to the open-ended questions revealed four themes related to students' experience with remote instruction: communication, flexibility, interaction, and empathy.

The predominant theme among students about what helped them during remote instruction was communication. Specifically, students indicated that timely, clear, and consistent communication was 
key. Two modes of communication were identified: email and virtual office hours. Timely communication helped students address uncertainty and confusion with new assignment formats and deadlines. In terms of email communication, there were two types of communication that students found most beneficial. Of the students that identified communication as important, $33 \%$ stated that timely, prompt email replies helped them to be successful. Secondly, 45\% stated that proactive and consistent emails from instructors, especially those containing details about assignments and changes in deadlines, were key. This aligns with prior research about the importance of email communication (Brooks \& Young, 2016; Levy, 2016).

Consistent communication from instructors showed that they were accessible to students even though instruction was remote. Additionally, quick feedback on assignments helped students feel that instructors were in a continued conversation about their work and learning. Creating shared expectation amongst all instructor in terms of prompt email replies is one way to address this. Instructors in the department of the current study, agree that at baseline email responses should be within 24 hours on weekdays. However, considering that students are engaging in more independent work, the instructor should aim for a faster response when able.

The second mode of communication identified as helpful by students was attending virtual office hours through video conferencing. Of the students that identified communication as important, students indicated that having opportunities to video conference with their instructors during office hours or their designated class time ensured that the timing worked for their schedule. However, students also indicated that flexibility in timing was important. Virtual meetings were beneficial for going over assignments in detail and in answering questions to provide clarification on material learned, while including verbal and non-verbal communication (Würtz, 2006).

Next, students identified flexibility as an integral factor to remote instruction success. Particularly, students identified flexibility in terms of assignment due dates and the types of assignments. The spring 2020 academic semester started with regular classroom instruction which abruptly and quickly transitioned to remote instruction. With these sudden changes, it is not surprising that students appreciated flexibility. Student responses revealed that it helped when instructors adjusted assignment type and format to fit the realm of remote learning. For example, some responses stated it was helpful when instructors "adjusted assignments to new mode," were flexible with the assignments required," "changed the format of assignments or got rid of ones that weren't possible anymore."

Secondly, it was helpful when instructors were flexible with assignments with respect to the needs of the students. Students revealed that assignments needed to be modified especially when they did not have all the necessary tools at home to complete the task. For example, students indicated that it helped when instructors "adjusted assignments to fit the needs of students" and "altered assignments because they were aware we might not have the necessary tools at home to complete the tasks accurately." Additionally, of the students that identified flexibility as important, $45 \%$ specified that extending deadlines and allowing students to adjust to remote learning were favorable factors. Students stated that this was an important element as they acclimated to a new learning environment, their home.

A major element that facilitated remote learning was instructors' use of virtual platforms that encouraged interaction and made material engaging. Particular platforms and resources identified as helpful were Zoom meetings, video lectures, audio lectures, virtual guest speakers, and Blackboard Collaborate. One student stated, "was great being able to bounce ideas off of others to get ideas or direction." Another stated, "I loved that my education professor introduced us to tools that we could implement into a remote learning environment by using them during our weekly virtual lessons." Thus, an important qualification is that students appreciated these platforms when they were used 
purposefully. They mentioned that classes would run smoothly when the virtual platform meetings were well planned out and had structure. Using virtual platforms, such as Zoom meetings, allowed for students to have authentic interactions with their professor and with other students about learning material. It provided consistency in creating a virtual learning environment analogous to that of regular, face-to-face instruction.

Lastly, 13\% students identified having an empathic instructor was helpful. For students, empathy meant that instructors provided encouragement and reassurance about the changing situation. Empathy also meant that instructors were understanding of students' at-home circumstances and resources. Students specified that they appreciated when socio-emotional support was shown through one-on-one Zoom meetings and through email check-ins. As one student wrote in the survey, having an understanding instructor checking-in made them "feel seen and not forgotten" throughout remote instruction.

Students were asked to describe how their remote instruction experience could have been improved. Interestingly, the same themes previously identified by students emerged from the data. After going through all of the responses to the second question and classifying the message units into categories, three codes emerged: communication, interaction, and flexibility. Most notably, $24 \%$ of students stated better communication between instructors and students would have enhanced their experience. Specifically, communication could have been enhanced by being "more timely." Of the student that identified that communication could have been better, $50 \%$ would have liked to have quicker turn around on emailed questions and concerns. Next, $50 \%$ of students indicated that clearer and more descriptive communication was necessary for explaining assignments and new schedules. With more regular communication, students noted that new assignments, due dates, and confusion over learning material could have been cleared up quickly and reducing stress. The vast majority of students mentioned email as the vehicle of choice for increased communication.

Another major element to improve remote instruction suggested by students was having more virtual meetings to facilitate interactions with their instructors and among their peers. Students desired a classroom feel through remote instruction. One student explained that they felt "like the interaction stopped." Using video conferencing platforms, such as Zoom could have helped to foster a classroom community feel and enhance communication between the instructors and students. This aligns with research about the contributions of high-context communication (Würtz, 2006).

During the spring 2020 semester, all courses moved from face-to-face to a remote method. Instructor approaches to remote instruction differed. Some continued to meet virtually in a synchronous manner. Others adjusted to an asynchronous form. Additionally, instructors used a plethora of platforms based on their knowledge and level of comfort. This variability may have added to the burden of inconsistency in term of level of interaction felt by students from one course to another.

As a response, the department made clear the format and frequency of meetings that each remote and hybrid course would adopt for the fall 2020 academic semester in the course description for registration. Additionally, by sharing the results of the survey, instructors have adopted norms and shared online platforms that have been particularly effective (described below). The predominant video conferencing platforms used and referenced most by students are Zoom and Blackboard Collaborate.

The last major theme that emerged from the data was flexibility. Seven percent of students stated that flexibility with types of assignment in particular could have helped to foster a more positive remote learning environment. Students stated that many in-class assignments did not translate well to remote instruction without modification. 
The themes-communication, flexibility, empathy, and interaction-align with previous research on effective remote instruction. Communication is the aspect most identified as important for students in the current study. This is in agreement with Fish and Wickersham (2009). They posit that frequent communication is key to remote instruction. Further, they explain that creating remote courses requires more than a simple translation of face-to-face materials and instruction to an online format. The material and virtual interactions need to be carefully considered. Students in the current study stated that when instructors used technology to facilitate interaction and make the material more interesting, they learned better. This is in line with Everett (2015) which found that students felt more engaged with their class and the learning material when their instructors made deliberate attempts to help them actively engage in the learning online. Moreover, Dixson (2010) examined that types of online interactions that were most engaging for students. She determined that students benefited from interactions in which the instructor facilitated student-to-student engagement around the course material.

Considering the notion that online, remote instruction requires deliberate planning over and above simply transitioning a course from face-to-face, professional development in this area is important. In the current study, we sought to learn from students via surveys about how to improve remote instruction. Further, we utilized resources, such as the PDS consortium which typically provides a plethora of professional development opportunities. However, in response to the educational climate, the professional development opportunities quickly shifted to enhancing the effectiveness of remote instruction. This is in line with Fish and Wickersham (2009) on the need for professional development targeted at planning remote instruction.

Additionally, in the context of teacher education there are required assignments with regulations on fieldwork hours and documentation necessary on student performance. This can create an additional layer of complexity with creating flexibility with assignments. As a response, faculty teaching the same or similar courses worked together to create alternative assignments that continued to conform to all requirements. All required assignments were switched to be created and delivered remotely. For example, teacher candidates were no longer able to conduct lessons face to face in schools nor record these lessons. So, students watched a video of a teacher teaching a lesson and were asked to expand upon the lesson. Additionally, students created pre-recorded, unedited instructional videos that could be used to teach a skill remotely. Another example is that students worked with schools in the field to conduct online, synchronous instructional groups to earn their fieldwork hours.

The students' responses provide snapshots of many of the elements that they believe helped or could have helped make their remote instruction experience a success. Interestingly, the same themes emerged with both survey questions. This shows that these elements are integral to remote instruction and when missing, are to the detriment of the students.

Strengths. Several features of the study contribute to its strength. First, survey data were collected from students at various points in their undergraduate and graduate studies. Additionally, data were collected from students in various majors within the department. Thus, the themes that emerged can be generalized to different populations of students in terms of their level and majors within the department. Next, students' responses were anonymous, encouraging respondents to provide accurate, honest answers. Two open questions were used to explore what students believed helped to make remote instruction successful and what could have been improved. Open-ended questions allow data to be collected in students' own words.

Limitations. A limitation of the current study is that not all students answered the open-ended questions. Of the 93 participants, 75 answered the first open-ended question and 72 answered the second open-ended question, which could create bias. Another limitation of the study is that there were 
not enough participants in each academic year (i.e., freshmen, sophomores, juniors, seniors, first year graduate students, and $2^{\text {nd }} / 3^{\text {rd }}$ year graduate students) to analyze if there was a statistical relationship between year and attitudes towards remote learning. However, based on the descriptive analysis, the themes that emerged from the data were the same irrespective of year. Future research may benefit from using this data with multiple academic departments and with more students to increase the external validity of the results. Additionally, considering the size of the department, there was a low response rate. With the low response rate there are, inherently, missing perspectives about what was worked and did not work. Nevertheless, by looking for similar themes among the responses received the study can highlight the common and most expressed viewpoints.

\section{Implications and Future Directions}

The survey data provided broad suggestions that can improve remote learning. However, each course will have its own needs and unique set of circumstances. It is important for instructors to work with their students to facilitate a conversation early on about what they believe will work best for a successful semester. Bringing students in on the conversation can shed light on their needs and their former experiences, and it also gives them ownership of the process. This can be facilitated through an online survey where students can express their previous experiences with remote instruction and communicate their needs.

Secondly, with a clear layout and routine for each week, students know what is expected of them. A course schedule that is flexible and referred to weekly sends a clear message of expectations and facilitate students feeling a sense of structure. Although the term remote is synonymous with distant or removed, it may be crucial for instructors to cultivate connections and create a classroom community feel with online learning. Often, remote instruction begets altered assignments and grading. Thus, clear and consistent communication helps students know what is expected of them and how to succeed. Finally, eliciting feedback from students throughout the course and at the end can help instructors reflect and make appropriate changes to improve their courses for remote instruction.

It is not surprising that flexibility is important with distance learning. Each student's learning environment is different. Students have varying access to resources which can impede or facilitate their ability to access learning materials or complete an assignment. Finding out ahead of time what resources students have access to and how they can be provided those resources can facilitate a smooth and equitable learning environment. Further, with the proliferation of virtual platforms, there are many opportunities to stimulate a classroom environment. Encouraging interaction provides opportunities for students to extend their learning, to receive direct guidance from their instructor, to have real-time feedback, and to collaborate with their peers.

The results of these surveys were shared in our department with faculty during a Zoom meeting at the end of the 2019-2020 academic year. As an outcome, faculty developed norms for remote instruction - for faculty and for students. Some of the norms included the following:

- Meet face to face (at least remotely) once a week

- Respond to emails within 24 hours during the work week

- Provide students with a weekly checklist, so they know what they need to accomplish

- Post a rubric for each major assignment so criteria are clear

- Provide office hours times when students can connect for questions and allow students to choose which method, they like for office hours - Zoom, email, or phone call 
- Provide meaningful feedback, so students can learn from their assignments. This includes formative feedback when appropriate

- Identify an agenda with posted materials ahead of time, so people have a chance to get organized before signing on to Zoom meetings

- Integrate some sort of community building into each class, such as using breakout rooms in Zoom

- Set expectations that students and instructors participate with both video and audio (if possible) during synchronous meetings

A shared discussion of the survey results allowed for valuable expression and reflection of the unprecedented semester. Creating the norms together, helped to facilitate consistency across the department and it assisted in clarifying the expectations of faculty to collectively meet students' needs. For example, faculty created a shared understanding of what "prompt" meant-a response that is within 24 hours. It also highlighted the need for professional development opportunities to help faculty learn ways to teach and respond to students remotely.

In response to these survey results, the PDS consortium at our college offered online professional development for a variety of stakeholders, including teacher candidates, college faculty, and school partners. Students' responses to the survey helped to determine important topics of discussion. The topics included how to respond to students in socio-emotional responsive ways and fostering resilience. Additionally, many faculty members led professional development sessions on using engaging online instruction. Sessions includes topics on using Google Classroom and Flipgrid in different contexts. All learning sessions were recorded and housed online to be accessed at any time by faculty as they implemented these features into their classes.

During each monthly faculty meeting, faculty spent the beginning of each meeting sharing on their remote teaching thus far. During this time, instructors shared their successes and areas for improvement. Collectively, faculty learned how to use breakout rooms on Zoom and how to manage student participation, how to use Perusall.com to engage students around articles and other readings, and how to use Loom (loom.com), Bitmojis (created via Google Slides), and Edupuzzle (edupuzzle.com) to create lessons and videos.

After eliciting student feedback, it is important to enact positive change to improve teaching practices. Thus, it is integral to provide faculty with knowledge, tools, and time to reflect and discuss so that they are prepared for the next step in remote and hybrid instruction.

\section{Declaration of Conflicting Interests}

The author declared no potential conflicts of interest with respect to the research, authorship, and/or publication of this article.

\section{Funding}

The authors received no financial support for this research.

\section{ORCID iD}

Selenid M. Gonzalez-Frey (Di) https://orcid.org/0000-0002-9186-0211 


\section{References}

Aiken, M., Vanjani, R., \& Martin, J. (2003). College student internet use. Campus-Wide Information Systems, 20,182-185. https://doi.org/10.1108/10650740310507371

Amendum, S., \& Liebfreund, M. (2019). Situated learning, professional development, and early reading intervention: A mixed methods study. The Journal of Educational Research, 112(3), 342-356.https://doi.org/10.1080/00220671.2018.1523782

Anderson, T., \& Dron, J. (2011). Three generations of distance education pedagogy. International Review of Research in Open and Distance Learning, 12(3), 80-97. https://doi.org/10.19173/irrodl.v12i3.890

Barbosa, T. \& Barbosa, M. (2019). Zoom: an innovative solution for the live-online virtual classroom. HETS Online Journal, $9(2)$.

Borko, H., Jacobs, J., \& Koellner, K. (2010). Contemporary approaches to teacher professional development. In P. Peterson, E. Baker, and B. McGaw (Eds.), International Encyclopedia of Education(vol. 7, pp. 548-556). Elsevier. https://doi.org/10.1016/B978-0-08-044894$\underline{7.00654-0}$

Brindley, R., Field, B. E., \& Lessen, E. (2008). What it means to be a professional development school. National Association of Professional Development Schools. https://napds.org/nine-essentials/

Bruner, R., Yates, B. \& Adams, J. (2008). Mass communication and journalism faculty and their electronic communication with college students: A nationwide examination. The Internet and Higher Education, 11(2), 136-111. https://doi.org/10.1016/i.iheduc.2008.06.001

Burdina, M., Krapotkina, I., \& Nasyrova, L. (2019). Distance learning in elementary school classrooms: An emerging framework for contemporary practice. International Journal of Instruction, 12(1), 1-16. https://doi.org/10.29333/iji.2019.1211a

Bushweller, K. (2005). Got mail? Teacher Magazine, 17(3), 49-50.

Darling-Hammond, L. (1994). Professional development schools: Schools for developing a profession. Teachers College Press.

Darling-Hammond, L., Hyler, M.E., Gardner, M. (2017). Effective teacher professional development. Learning Policy Institute.

DeMonte, J. (2013). High-quality professional development for teachers: Supporting teacher training to improve student learning. Center for American Progress.

Dixson, M. (2010). Creating effective student engagement in online courses: What do students find engaging? Journal of the Scholarship of Teaching and Learning, 10(2), 1-13.

Duran, R., Kelly, L., \& Keaten, J. (2005). College faculty use and perceptions of electronic mail to communicate with students. Communication Quarterly, 51(2), 46-54. https://doi.org/10.1080/01463370500090118

Everett, D. (2015). Adding value: Online student engagement. Information Systems Education Journal, 13(6), 68-76.

Fish, W., \& Wickersham, L. (2009). Best practices for online instructors. The Quarterly Review of Distance Education, 10(3), 279-284.

Goffee, W., \& Sosin, K. (2005) Teaching with technology: May you live in interesting times. Journal of Economic Education, 36(3), 278-292. https://doi.org/10.3200/JECE.36.3.278-291

Goldstein, D., Popescu, A., \& Hannah-Jones, N. (2020). As school moves online, many students stay logged out. The New York Times. https://www.nytimes.com/2020/04/06/us/coronavirus-schools-attendance-absent.html 
Holmes, A., Signer, B., \& MacLeod, A. (2010). Professional development at a distance: A mixed method study exploring inservice teachers' views on presence online. Journal of Digital Learning in Teacher Education, 27(2), 76-85. https://doi.org/10.1080/21532974.2010.10784660

Keazer, A. \& Moriarty, D. (2000). Expanding our understanding of student leadership development: A study exploring gender and ethnic identity. Journal of College Student Development, 41(1), 55-69.

Kim, Y., \& Sax, L. (2009). Student-faculty interaction in research Universities: Differences by student gender, race, social class, and first-generation students. Research in Higher Education, 50, 437459. https://doi.org/10.1007/s11162-009-9127-x

Kuh, G. \& Hu, S. (2001). The effects of student-faculty interactions in the 1990s. The Review of Higher Education, 24(3), 309-332. https://doi.org/10.1353/rhe.2001.0005

Kurt, S. (2020). Lev Vygotsky - Sociocultural theory of cognitive development. Educational Technology. https://educationaltechnology.net/lev-vygotsky-sociocultural-theory-ofcognitivedevelopment/

Lau, L. (2003). Institutional factors affecting student retention. Education, 124(1), 126-136.

Lave, J. (1988). Cognition in practice: Mind, mathematics, and culture in everyday life. Cambridge University Press.

Lave, J. \& Wenger, E. (1991). Situated learning: Legitimate peripheral participation. Cambridge University Press. https://doi.org/10.1017/CBO9780511815355

Ledbetter \& Finn (2018) Perceived teacher credibility and students' affect as a function of instructors' use of PowerPoint and email, Communication Education, 67(1), 31-51. https://doi.org/10.1080/03634523.2017.1385821

Levy, D. (2016). Contemplate your email. The Chronicle of Higher Education, 62(31) B20.

Lima, C., \& Brown, S. (2007). ICT for development: Are Brazilian students well prepared to be global citizens? Educational Media International 44(2), 141-53. https://doi.org/10.1080/09523980701295141

Mena, M. (2007) E-learning quality: A look towards the demands of its good practices. Journal of Cases on Information Technology, 9(2).

Pascarella, E. (2006). How college affects students: Ten directions for future research. Journal of College Student Development, 47(5), 508-520. https://doi.org/10.1353/csd.2006.0060

Pence, H. (2007). Preparing for the real web generation. Journal of Educational Technology Systems 35(3), 347-56. https://doi.org/10.2190/7116-G776-7P42-V110

Sidelinger, R. J., Bolen, D. M., McMullen, A. L., \& Nyeste, M. C. (2015). Academic and social integration in the basic communication course: Predictors of students' out-of-class communication and academic learning. Communication Studies, 66, 63-84. https://doi.org/10.1080/10510974.2013.856807

Strauss, L. \& Terenzini, P. (2007). The effects of students in and out of class experiences on their analytical and group skills: A study of engineering education. Research in Higher Education, 48(8), 967-992. https://doi.org/10.1007/s11162-007-9057-4

Thompson, M. (2001). Informal student-faculty interaction: Its relationship to educational gains in Science and mathematics among community college students. Community College Review, 29(1), 35-57. https://doi.org/10.1177/009155210102900103

Vygotsky, L. (1978). In mind and society. Harvard University Press. 
Waldeck, J., Kearney, P., \& Plax, T. (2001). Teacher email message strategies and students' willingness to communicate online. Journal of Applied Communication Research, 29 (1), 54-70. https://doi.org/10.1080/00909880128099

Würtz, E. (2005). Intercultural communication on Web sites: a cross-cultural analysis of Web sites from high-context cultures and low-context cultures. Journal of Computer-Mediated Communication, 11(1), 274-299. https://doi.org/10.1111/j.1083-6101.2006.tb00313.x 